\title{
The social network of solidarity with migrants: The role of perceived injunctive norms on intergroup helping behaviors
}

\author{
Antoine Roblain $^{1}$ (D) | Mado Hanioti ${ }^{1,2}$ | Emilien Paulis ${ }^{3}$ (D) | Emilie Van Haute ${ }^{3}$ | \\ Eva G. T. Green ${ }^{4}$
}

${ }^{1}$ Center for Social \& Cultural Psychology, Université Libre de Bruxelles, Bruxelles, Belgium

${ }^{2}$ Fond National pour la Recherche Scientifique, Brussels, Belgium

${ }^{3}$ Cevipol, Université Libre de Bruxelles, Bruxelles, Belgium

${ }^{4}$ Institute of Psychology, University of Lausanne, Lausanne, Switzerland

\section{Correspondence}

Antoine Roblain, Center for Social \& Cultural Psychology, Université Libre de Bruxelles CP 122, 50 av. F.D. Roosevelt, B-1050 Bruxelles, Belgium.

Email: aroblain@ulb.ac.be

Funding information Belgian Federal Science Policy Office, Grant/Award Number: BR/175/A5/ PUMOMIG

\begin{abstract}
Using an ego-centered network approach, we examine across two studies whether and how injunctive network norms-behaviors that are approved by alters-are related to majority members' decisions to participate in helping actions supporting migrants. We hypothesize that the more people perceive their personal social networks as positive toward humanitarian actions for migrants, the more they consider their opinions on migration issues as self-defining, and the more they are willing to mobilize in helping behaviors. With a name generator approach, we collected personal social network data among majority members of Belgian, mobilized volunteers (Study 1 , $N=204$ ) and Swiss, non-mobilized participants (Study 2, $N=247$ ). Results demonstrate the impact of injunctive network norms in promoting and maintaining helping actions for migrants, and the role of self-defining attitudes. Overall, the results highlight the importance of injunctive norms within personal social networks for participation in intergroup helping behaviors.
\end{abstract}

\section{KEYWORDS}

identity, intergroup helping, migration, norms, social networks, volunteerism

\section{1 | INTRODUCTION}

Since the beginning of 2015, a significant number of migrants have made their way to Europe. Many citizen initiatives supporting migrants have emerged across Europe in order to respond to the perceived humanitarian crisis (e.g., Rea, Martiniello, Mazzola, \& Meuleman, 2019). Since then, research in various disciplines-such as political science, human rights law, and social psychology-have examined possible factors explaining citizens' mobilization in favor of migrants (e.g., Baumgärtel \& Oomen, 2019; della Porta, 2018; Kende, Lantos, Belinszky, Csaba, \& Lukács, 2017; Rea et al., 2019). The present article contributes to this line of research by uncovering the role played by personal social networks of national majority members in participation in helping migrants.

While social psychological literature on intergroup relations addressing immigration issues has primarily focused on negative phenomena such as discrimination, racism or prejudice, less attention has been devoted to positive intergroup behaviors, such as helping behaviors. Moreover, existing research has mainly considered individual- or interpersonal-level antecedents of helping behaviors (e.g., Clary \& Snyder, 1991).

However, research on the role of social inclusion has recently developed, underscoring the critical influence of the social environment in defining volunteers' identity and participation in helping behaviors (e.g., van Leeuwen \& Zagefka, 2017; Simon, Stürmer, \& Steffens, 2000; Stürmer, Snyder, \& Omoto, 2005). While the impact of whether and why belonging to an opinion-based group have already been addressed, research has neglected the role played by personal social networks ${ }^{1}$ on participation in such actions. This absence is surprising given the existence of close ties between social networks and social mobilization (Klandermans, 2014, p. 20).

${ }^{1}$ In the present article, social networks will be considered as a set of relationships with relevant others in which individuals are embedded (Crossley et al., 2015). 
With two cross-sectional studies conducted among mobilized and non-mobilized citizens, we aim to fill this gap by examining whether and how personal social networks relate to intergroup helping behaviors. More specifically, we argue that perceived injunctive norms-behaviors that are commonly approved by others (Cialdini, Reno, \& Kallgren, 1990)-established in the personal social network are related to both citizens' intention to mobilize and volunteers' willingness to continue to participate in helping actions in favor of migrants.

Our research focuses specifically on helping behaviors. Solidarity actions can take different forms, such as volunteerism, donating to the disadvantaged, political activism or collective actions (Louis et al., 2019). Arguably, two broad forms of solidarity-based actions can be distinguished, benevolent support and activist support (Thomas \& McGarty, 2018). Benevolence, or helping, aims at alleviating the suffering of people in need. Activism, in turn, aims at changing the socio-political system. The two differ in terms of actions, engagement, frequency, appraisal, emotions and outcomes (Thomas \& McGarty, 2018). Benevolence has been studied at the individual and interpersonal level with little consideration of the social context and social norms. In both Studies 1 and 2, we focus on benevolent support through the act of giving humanitarian help to migrants, and examine the link between perceived injunctive norms of the personal social network and intentions to participate in helping behaviors.

\section{1 | Antecedents of helping behaviors}

Past research has shown that people are motivated to engage in helping behaviors not only to meet the needs of the recipient, but also to satisfy the ingroup's needs (Nadler, 2002) or to fulfill personal needs and interests, such as learning new skills or finding meaning in life (Omoto \& Snyder, 1990). Researchers investigating motivations underlying these behaviors have sought to identify possible determinants from a multilevel perspective, including both the micro (individual) and meso levels (i.e., social inclusion in groups and networks) (Penner, Dovidio, Piliavin, \& Schroeder, 2005; Snyder \& Omoto, 2008).

On the one hand, research adopting an individual-level perspective is primarily concerned with the origins of helping behaviors in humans (e.g., neural or evolutionary basis) and in individual differences in these tendencies. A functionalist approach (Penner et al., 2005) emphasizes individual purposes leading to the actions, and the functions being served by engaging in such behaviors (e.g., Snyder, 1993). Most notably, the widely used Volunteer Functions Inventory developed by Clary and Snyder (1999) identifies six different functional motivations for performing helping behaviors (i.e., value, understanding, esteem enhancement, career, social concerns and protection motivation).

On the other hand, research adopting a meso-level perspective has argued that helping behaviors toward an outgroup are shaped by individuals' embeddedness in social structures, such as groups and social networks. These social structures are a source of social identification, establish norms, and allocate resources that encourage participation in such actions (Klandermans, 1984). Most of the research adopting this meso-level perspective has investigated how identification with a social group influences the tendency to act-or not-in favor of an outgroup member (e.g., van Leeuwen \& Zagefka, 2017). This literature has largely been influenced by the Social Identity Theory (Tajfel \& Turner, 1986), which argues that, when a group membership is salient, people are likely to demonstrate strong favoritism toward ingroup members as opposed to members of other groups. We want to contribute to this line of research and other more recent models (for instance, Nadler, 2002; the Intergroup Helping as Status Relations Model) based on identity dynamics, by highlighting other reasons for engaging in helping behaviors and, more specifically, the role played by norms and social networks.

\subsection{Role of norms and social networks in motivating helping behaviors}

In this article, we argue that participation in helping behaviors for migrants is driven by the proximal normative climate. As perceived normative contexts play a critical role in every human behavior (Fishbein \& Ajzen, 1975), prosocial and intergroup helping behaviors are influenced by perceptions of how one is expected to behave in a particular context (e.g., Gabriel et al., 2001; Shang \& Croson, 2009). Indeed, the role of a normative climate in solidarity movements with migrants has already been suggested by Kende et al. (2017, p. 274): "in the context of the refugee crisis, volunteerism was the normatively appropriate response among those who held pro-refugee opinions, based on both their attitudes and the norms of their ingroup".

However, despite the evidence that social networks establish prevalent norms, and have a critical influence on individuals' attitudes and behaviors (McPherson, Smith-Lovin, \& Cook, 2001; Sinclair, 2012; Zuckerman, Valentino, \& Zuckerman, 1994), a network perspective has up to now been largely absent in the social psychological literature on intergroup helping. Yet, in addition to providing essential resources needed for mobilization (Klandermans, 1984), networks are also contextual environments establishing norms related to ingroup and intergroup relations (e.g., Paluck, 2011). By using a social network methodology, we contribute to the literature on helping behaviors and argue that perceived injunctive norms established in the personal social network are linked to intergroup helping behaviors.

We employ an ego-centered social network approach (see Appendix 1 for ego-centered social network visualization) (Burt, 1984; Crossley et al., 2015). This methodology is commonly used in a wide range of studies on attitudes and behaviors, such as political participation (protest, campaigning, voting, etc.), beliefs (Sinclair, 2012; Zuckerman, 2005) or health issues (smoking habits, disease infection, obesity, etc.) (Christakis \& Fowler, 2009). The ego-centered network approach allows the collection of several key facts of one's personal social environment. First, these personal 
social networks chart an individual's "alters"-the people they consider most important to them. Second, both qualitative (level of intimacy) and quantitative (contact frequency, perceived alters' attitudes and expectations regarding a certain issue) data related to these alters are collected. With this information, it is then possible to describe network composition (with whom), its structure (how people are connected), and the norms within one's personal social network.

We postulate that injunctive network norms are linked to intentions to participate in helping behaviors in favor of migrants (see Figure 1, path a). In Study 1, we analyze the personal social networks of mobilized citizens and investigate the relationship between these injunctive network norms and volunteers' intentions to persist helping migrants. In Study 2, we examine, among non-mobilized citizens, the link between injunctive network norms and the intentions to provide humanitarian assistance to migrants. Moreover, we investigate in this second study how this meso-level social structure (i.e., social network) is related to individual-level predictors of participation in helping actions. More specifically, we examine the extent to which immigration attitudes are self-defining or not.

\section{3 | Internalization of external norms versus network selection}

We postulate that external norms (i.e., injunctive network norms) will be perceived as cues that define how an individual should or should not act. The more injunctive network norms are in favor of solidarity toward migrants, the more individuals should consider their attitudes toward this social issue as "self-defining" (path b, Figure 1). An attitude is self-defining when it is considered personally relevant and important, and thus defines the individual's sense of self (see Zunick, Teeny, \& Fazio, 2017). Injunctive network norms can indeed lead to the internalization of external norms (Crandall, Eshleman, \& O'Brien, 2002; Sherif, 1966). Instead of merely conforming to external norms, individuals sometimes integrate these norms in their identity. When norms become particularly salient, individuals go through a period of adaptation, which leads them to internalize these norms and to consider them as part of their own personal and social identity (Hogg \& Abrams, 1988). Following this line of thought, we assume that injunctive network norms about humanitarian assistance to migrants could be internalized, and that attitudes toward immigration could be integrated in one's identity.

Furthermore, self-defining attitudes have proven to be particularly stable and predictive of behavior (Petty \& Krosnick, 1995). For instance, Zunick et al. (2017, Study 4) showed that self-definition can be related to intentions to spontaneously advocate in favor of a self-defining attitude, and to engage in actual behavior. In line with this idea, Turner-Zwinkels, van Zomeren, and Postmes (2015) demonstrated that identity content is a significant predictor of action engagement. To quote them, "what it means to be me" becomes analogous to "what it means to be a political activist" (TurnerZwinkels et al., 2015, p. 435). Indeed, Kende et al. (2017) showed that the way people identify themselves-in this case, with an opinion-based group-relates to volunteerism in favor of migrants. Consequently, we expect that the more attitudes toward migrants are considered as self-defining, the more individuals intend to act in consonance with their attitudes (path c, Figure 1).

Finally, regarding network structure, we focus on network density, which is commonly used to estimate the level of network connectedness (i.e., how well [dis]connected a network is) (Crossley et al., 2015). Network density is defined as the level of compactness of alters' connections. In other terms, a high density of a network indicates that alters are well connected to each other, while low density reflects low connectedness. Though the direct link between network density, intergroup attitudes and behaviors remains relatively unclear (Crossley et al., 2015), research suggests that this structural feature is likely to moderate the effects of a network's social norms. Indeed, network density appears to reinforce processes of social influence and norm sharing in social networks (Bienenstock \& Oliver, 1990; Knoke, 1990; Lazer, Rubineau, Chetkovich, Katz, \& Neblo, 2010; Paulis, 2018). Hence, we argue that social network density moderates the relation between perceived injunctive norms and helping behaviors (path $d$, Figure 1), and the extent to which immigration attitudes are self-defining (path $e$, Figure 1). When the network's is density is high, the effect of injunctive (or descriptive) norms on the intention to participate in helping actions will be stronger than when network density is low.

\section{2 | STUDY 1}

The goal of this first study is threefold. First, we aim to highlight the descriptive characteristics of network structures and injunctive network norms among a mobilized sample. Following our assumption of a positive correlation between injunctive network norms toward helping actions for migrants and participation in these actions, we expect that volunteers' networks will be perceived as having, on average, positive to very positive attitudes toward humanitarian help for migrants. Second, we test the link

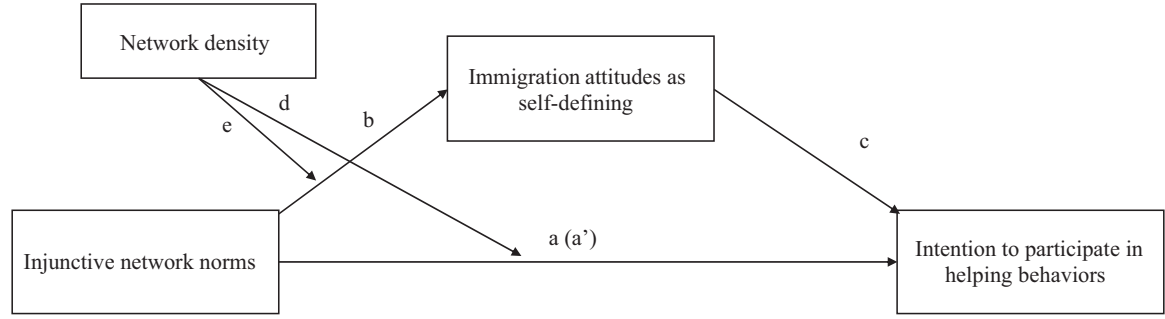

FIGURE 1 Indirect effect hypothesis predicting intention to participate in helping behaviors in favor of migrants 
between these norms and the intention to participate in future helping actions. Additionally, we test whether this link persists after controlling for explicit initial motivations, which are generally used to predict such behaviors (e.g., Omoto \& Snyder, 2002). Finally, we also investigate the effects of both injunctive and descriptive network norms. Contrary to injunctive norms that reflect "what most people approve or disapprove of", descriptive norms refer to "what most people do" (Cialdini, Kallgren \& Reno, 1991). For example, Smith and Louis (2008) recently showed that both norms predict political attitudes. In the present study, we operationalize descriptive network norms about helping behaviors through the proportion of alters participating in helping activities for migrants. While intuitively one would assume that injunctive and descriptive norms are positively correlated, we also examine the independent links between these two norms and volunteers' intentions to mobilize in the future.

Since the so-called "refugee crisis" of 2015, Belgium has experienced the emergence of a wide range of solidarity initiatives providing support to asylum seekers, refugees and, more broadly, migrants. The Citizen's Platform for Refugee Support was born in Brussels during the summer of 2015, when waves of thousands of migrants reached the Belgian capital. While their humanitarian and political activities were primarily focused on people wishing to receive asylum in Belgium, the Citizen's Platform volunteers have, since 2017, provided humanitarian assistance to migrants coming to, passing through and waiting in Belgium, whose main objective is to reach the United Kingdom. Taking advantage of a legal framework allowing aid provided for humanitarian reasons to people in an irregular situation in Belgium, the Citizen's Platform's main activity is to find accommodation for up to 300 individuals per night. According to the Platform's coordinators, around 8,000 volunteers hosted a migrant in their homes at least once between August 2017 and March 2019 (Vandevoordt, 2019). With the support of the Platform's coordinators, we conducted an online survey among these mobilized citizens in 2018.

\section{1 | Method}

\subsection{1 | Participants}

Two hundred and four volunteers (179 females) of the Citizen's Platform completed an online questionnaire. ${ }^{2}$ The questionnaire was disseminated on Facebook pages of the citizen movement by the research team and by the coordinators of the movement. Data collection took place between June and July 2018. Respondents

\footnotetext{
${ }^{2}$ Because the agreement between the association helping with the dissemination of the Study 1 questionnaire and the research team stipulates the confidentiality of the data, we cannot make data for Study 1 publicly available. However, the questionnaire is publicly available on the following link: https://osf.io/f4uxg/. These materials are those of Study 2. Because the agreement between the association helping with the dissemination of the Study 1 questionnaire and the research team stipulates the confidentiality of the data, we cannot make data for Study 1 publicly available.
}

participated in activities providing humanitarian assistance to migrants: $73.5 \%$ of the respondents had hosted a migrant prior to completing the survey and the rest had provided other kinds of assistance (e.g., making donations or helping to coordinate the initiative).

\subsection{2 | Measures}

\section{Volunteers' initial motivations}

We measured volunteers' explicit motivations to help migrants with 12 items-two items for each of the six dimensions of the Volunteer Functions Inventory (Clary et al., 1998): Social factor ("My friends volunteer" and "People I'm close to want me to volunteer") ( $r=.25$ ); Values factor ("I am concerned about those less fortunate than myself" and "I can do something for a cause that is important to me") ( $r=.15$ ); Protective factor ("No matter how bad I've been feeling, volunteering helps me to forget about it" and "Volunteering helps me work through my own personal problems") ( $r=.60)$; Career factor ("I can make new contacts that might help my business or career" and "Volunteering experience will look good on my resume") ( $r=.67)$; Enhancement factor ("Volunteering increases my self-esteem" and "Volunteering makes me feel better about myself") ( $r=.61$ ); Understanding factor ("Volunteering allows me to gain a new perspective on things" and "I can explore my own strengths") ( $r=.31$ ). Participants indicated the level of importance (from 1 Not at all important to 4 Very important) they attach to each of these motivations in their choice to participate in Citizen's Platform activities.

We performed an exploratory factor analysis with the items from the Volunteers Functions Inventory using the unweighted least squares procedure with an Oblimin rotation. This analysis indicated five factors explaining $67.73 \%$ of variance. The items concerning Enhancement and Protective motivations loaded on the same factor. The items measuring the other four dimensions loaded on independent factors (i.e., the two items measuring Social Motivation loaded on the same factor and so on).

\section{Injunctive and descriptive network norms}

We adopted a name generator approach to collect personal social network data. This method comprises asking participants to name people (alters) with whom they have some social contact. Depending on the aims of the research, the instructions can vary from naming people with whom they have frequent social contacts ("frequentcontact others"), people with whom they communicate about personal matters ("important matters discussant") or people they consider central to their lives ("significant other"). Because we were interested in the possible effect of perceived injunctive norms, we adopted the third approach, namely the affective approach, which has a particular value for research interested in the role of personal network in shaping behaviors (Marin \& Hampton, 2007). We therefore invited our participants to name up to 7 people they consider central to their lives (i.e., significant others). We opted to limit the maximum number 
of alters to 7, in order to avoid discouraging participants when providing information about each alter (Marsden, 2011; Merluzzi \& Burt, 2013). After naming these individuals, participants were asked a series of questions about each of these "significant others". One of these pieces of information concerned the perception of alters' attitudes toward humanitarian help provided to migrants. Participants were asked to answer questions for each alter, on a scale from 1 Strongly Disagree to 4 Strongly Agree: "To what extent do you think this person agrees or disagrees with the assistance provided to migrants?" Injunctive norms about helping behaviors in favor of migrants were operationalized as the mean of perceived alters' attitudes. Moreover, we assessed the perceived involvement of alters in helping actions for migrants. Participants indicated, for each alter, whether he or she had participated in the past, was currently participating, or had ever participated in helping activities for migrants. We operationalized descriptive network norms as the proportion of alters engaged in activities (i.e., the number of alters perceived as involved in helping activities divided by the total number of alters). Finally, participants were also asked to provide the type of relationship that they have with each alter (i.e., spouse, close family, extended family, friend, colleague, organization or association member, neighbor or acquaintance, professional advisor, or other).

\section{Network density}

In addition to information about the relations between themselves and alters, we invited respondents to provide their perceptions of the links among the alters. Concretely, participants were in front of a table matrix referring to their alters' names in rows and columns. For each dyadic relation, they had to pinpoint whether or not these two people knew each other (e.g., "Does Alter1 knows Alter2? Yes or No"). Often neglected in research adopting an ego-network approach, this information allows us to examine personal networks as genuine small socio-metric networks. Therefore, we are able to take into consideration the network's structural characteristics, such as density (Aeby, 2016). We measured network density of the alters' relations as the ratio of the number of existing ties among alters divided by the number of all possible ties among them (Crossley et al., 2015):

$$
\text { Ego network density }=\frac{N \text { actual ties }}{N \text { pontential ties }}
$$

Potential ties $=\frac{n(n-1)}{2}$ where $n$ is the number of alters.

The measure ranges continuously from 0 (no actual ties among alters) to 1 (every possible tie among alters is an actual tie). Appendix 1 presents some ego-network visualizations produced with our data, and shows how the density of the respondents' personal networks can lead to variations in network structure (from sparse to dense).

Intention to participate in helping actions

We used a single item reflecting the intention to participate in the main activity organized by the citizen movement (host migrants): "To what extent do you intend to host one or more migrants by the end of the year (i.e., within the next 6 months)?" Participants were asked to answer the questions on a scale from 1 (Not at all probable) to 4 (Very probable).

\subsection{Results}

\subsection{1 | Descriptive analysis}

The name-generating procedure shows that most survey participants (81\%) named up to 7 alters. People named on average 6 to 7 people $(M=6.55)$, and a large part of the respondents is located close to this mean ( $S D=1.15)$. In terms of density, more than a quarter of the networks reach the maximum value of "1" (26\%) and show a phenomenon of perfect network clique, where everybody is connected to everybody. The remaining networks display more variation, as indicated by the standard deviation $(S D=0.24)$. The minimum value is 0.05 and the overall mean is rather high $(M=0.72)$.

Concerning the composition of our networks, respondents were asked to provide their perceived level of agreement of each alter regarding assistance to migrants. The means by network suggest that the participants were on average exposed to very positive attitudes concerning assistance to migrants in their personal social networks $(M=3.48)$, with a large proportion concentrating close to the mean $(S D=0.46)$. The distribution reveals that $15 \%$ of respondents reached the maximum value for the variable "perceived injunctive norm", meaning that they operate in a totally homogeneous and positive network toward migrant assistance. Only $20 \%$ of respondents display a network where the average is lower than 3. Moreover, $47.1 \%$ of the participants declared that half of their alters had been involved in such helping actions. On average, participants said that $42.1 \%$ of their alters had previously provided assistance to migrants $(S D=0.27)$. Finally, friendship appears to be one of the most dominant relations in our sample of "significant others", with $36.7 \%$ of alters falling into this category. Spouses represent $8.3 \%$, whereas close and extended relatives represent $43.2 \%$ of the sample, when added together. Weaker social ties, such as colleagues (4.8\%), people met in organization/association contexts (3.6\%), acquaintances (1\%) or professional advisor ( $0.6 \%)$, are only scarcely mentioned as alters.

The bivariate statistics support our prediction that Injunctive and Descriptive network norms are positively related to the Intention to participate in helping migrants (see Table 1). These network norms are, unsurprisingly, positively correlated with Social motivations and negatively with more egoistic motivations (i.e., Career, Protective and Enhancement motivations). Finally, Intention to participate in helping behaviors is positively related to Understanding Motivation.

\subsection{2 | Regression analysis}

A multiple regression analysis was conducted with Intention to Participate in Future Helping Behaviors as the criterion variable 
TAB LE 1 Descriptive statistics and bivariate correlations (Study 1)

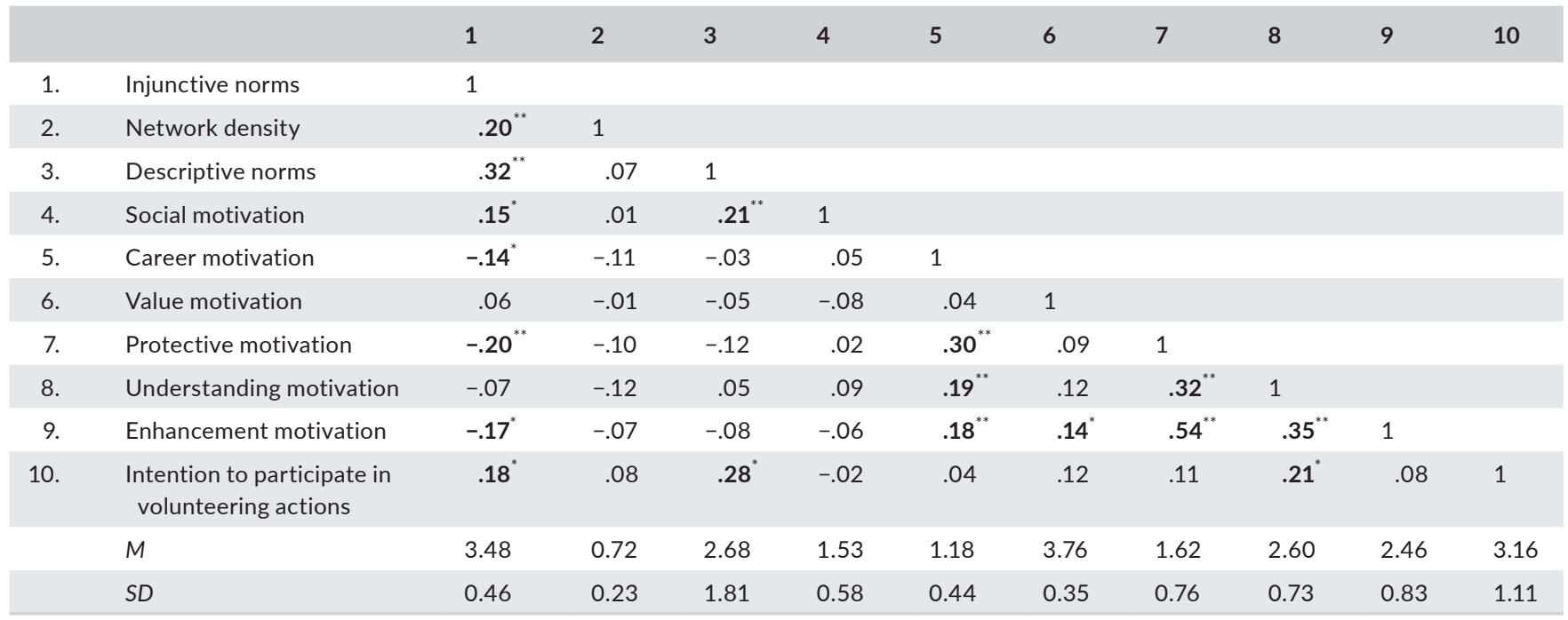

Notes: Values in boldface are statistically significant.

$N=204$,

${ }^{*} p<.05$,

${ }^{* *} p<.01$.

TABLE 2 Multiple regression analysis predicting intention to participate in helping actions (Study 1)

\begin{tabular}{lcc} 
& \multicolumn{1}{l}{$\boldsymbol{t}$} \\
\hline Injunctive network norms & 0.16 & $2.52^{* *}$ \\
\hline Network density & 0.05 & 0.84 \\
\hline Injunctive norms* Density & -0.02 & -0.26 \\
\hline Prior activities & 0.54 & $9.17^{* *}$ \\
\hline Descriptive network norms & 0.13 & $2.08^{*}$ \\
\hline Descriptive norms ${ }^{*}$ Density & -0.11 & -1.71 \\
\hline Initial motivations & & \\
Social motivation & -0.08 & -1.36 \\
Career motivation & -0.04 & -0.69 \\
Value motivation & 0.07 & 1.20 \\
Protective motivation & 0.13 & 1.81 \\
Understanding motivation & 0.16 & $2.49^{*}$ \\
Enhancement motivation & -0.13 & -1.85 \\
$R^{2}$ & & 0.48 \\
\hline
\end{tabular}

Note: Values in boldface are statistically significant. When sociodemographic variables (i.e., age, gender) and the total number of alters are included as control variables, the result pattern remains identical. Injunctive network norms, network density and descriptive network norms were mean centered. We used centered variables to calculate our interaction variables.

$N=204$,

${ }^{*} p<.05$,

${ }^{* *} p<.01$.

(see Table 2). Injunctive and Descriptive Network Norms, Network Density, the interaction between Network Density and Injunctive Network Norms, and Volunteers' Initial Motivations were entered as predictors. To control for prior assistance provided to migrants, we included a dichotomous variable on whether participants had hosted (or not) a migrant prior to participation in the survey. The multiple regression analysis confirms the pattern of the bivariate correlations. As predicted, the analysis shows that Injunctive and Descriptive Network Norms are positively associated with the intention to participate in future helping behaviors, all other variables remaining constant. Second, Understanding Motivation also appears to be important: the more people participated in Citizen Platform to learn more about themselves and gain a new perspective on things, the more they report high intentions to continue to engage in helping behaviors. Third, having previously accommodated a migrant is linked to the willingness to do so in the future. Finally, Network Density and the interaction variable between Network Density and Injunctive Norms are not related to the Intention to Participate.

\section{3 | Discussion}

Study 1 highlights that volunteers' personal social networks are characterized by injunctive norms that are almost exclusively (or unanimously) positive toward humanitarian help for migrants. In other words, volunteers reported the people they consider most important to them as having, on average, strong positive attitudes toward this particular helping action. This result provides support for our prediction regarding the link between involvement in helping behaviors and injunctive network norms. Moreover, these norms appear to be related to the volunteers' intentions to engage in a helping behavior, even after controlling for initial motivations. Furthermore, no causal link can be suggested by our results given the correlational nature of our data. 
Regarding the role of descriptive network norms, our results highlight that the injunctive norms are linked to descriptive norms, operationalized as the proportion of alters who are already active in helping actions for migrants. These descriptive norms are related to intentions to host a migrant, suggesting that both types of norms are independently linked to behavioral intentions to help minorities. These results are in line with Smith and Louis' study (2008) showing the effect of both injunctive and descriptive group norms on political attitudes.

Finally, the intention to participate in humanitarian helping actions is also related to volunteers' initial Understanding Motivation, akin to willingness to gain new insights on oneself and on the immigration issue. Indeed, this is consistent with Omoto and Snyder's (1995) findings that "the opportunity to have personal, self-oriented, and perhaps even selfish functions served by volunteering was what kept volunteers involved" (p. 684).

Although these results support our predictions, the study was carried out with a specific population (i.e., mobilized participants) and in a specific national context (i.e., Belgium), where the issue of immigration and humanitarian aid for migrants is very prominent. Therefore, Study 2 complements our findings and provides additional support to our predictions.

\section{3 | STUDY 2}

The aim of Study 2 is twofold. First, Study 2 aims to replicate, with a qualitatively different sample, the results of Study 1 . Study 2 applies our predictions to citizens who are a priori not engaged in social initiatives providing humanitarian help to migrants. Moreover Study 2 differs in the national context where the data collection took place. While Study 1 was conducted in Belgium, where many citizen initiatives have emerged to provide humanitarian support since 2015 (Mescoli et al., 2019), Study 2 was undertaken in Switzerland. Although Switzerland is characterized by a well-established protest culture and by a relatively high rate of participation in politics (Bader, 2018; Hutter \& Giugni, 2009), social mobilization for immigrants or against the reception of new asylum seekers is, contrary to Belgium, limited and infrequent (Rosenberger, 2018). Despite these contextual differences, we forecast the same relationship between injunctive network norms and intention to participate in helping behaviors. Finding common patterns in these two contrasting contexts would strengthen our findings.

In this second study, we further test the indirect link presented in Figure 1. We expect that meso-level social structures (i.e., social networks) relate to individual-level predictors of participation in helping behaviors. More specifically, we assume that stronger injunctive network norms in favor of solidarity-based actions for helping migrants are related to higher proportions of individuals who consider their attitudes toward this social issue as "self-defining", and higher proportions of individuals acting in accordance with their attitudes. Finally, we examine the extent to which network density moderates the relation between injunctive norms and intention to participate.

\section{1 | Method}

\subsection{1 | Participants}

Two hundred and eighty participants completed an online questionnaire (88 females; $M_{\text {age }}=35.91 ; S D=15.59$ ). Participants were all Swiss nationals and descendants of at least one nativeborn parent. Thirty-three participants were excluded from the analyses because they did not fulfill both criteria. The analyses were therefore carried out on a sample of 247 respondents. Recruitment was made via online social networks using a snowball procedure.

\subsection{2 | Measures}

\section{Injunctive network norms and Network density}

The same measurement tools as Study 1 (the name generator and affective approach) were used to collect personal social network data, with the exception that perception of alters' attitudes toward humanitarian help for migrants was measured on a scale ranging from 1 Strongly Disagree to 5 Strongly Agree, instead of a 4-point scale. Participants were asked to give their perception of each alter's attitude toward the following affirmation: "If the need arises, humanitarian aid should be provided to people who have been refused asylum and are therefore undocumented in Switzerland, even if this aid is illegal."

\section{Self-defining self-report measure}

Based on Zunick et al. (2017), self-defining function of immigration attitudes was measured on a 7-point Likert-type scale ranging from 1 (Don't agree at all) to 7 (Totally agree) combining two items ("My opinion about immigration is an important part of my identity" and "My opinion on migration policies in Switzerland shows what kind of person I am") $(r=.87)$.

\section{Intention to participate in helping behaviors for migrants}

In Study 1, we used a single item to measure the respondents' intention to engage in helping actions. To overcome this limitation, we opted in Study 2 for multiple items measuring participants' intention to engage in helping actions. In accordance with a scale developed by Kende et al. (2017), we use four items ( $\alpha=0.86$ ), measuring the intention to engage in four different types of humanitarian action through helping vulnerable migrants in Switzerland ("I would help by temporarily housing one or more asylum seekers or undocumented migrants in my home, even if this can be considered illegal in Switzerland", 3 "I would pay money to an association that helps people who have been refused asylum in Switzerland", "I would donate clothes or other useful things to people denied asylum in Switzerland",

${ }^{3}$ This item refers to a non-normative action. These actions are qualitatively different from normative actions (see for instance, Becker and Tausch, 2015). However, items were highly correlated. If separated into normative and non-normative actions, the result pattern is identical for both. 
"I would give my time to participate in the activities of an association that helps people who have been refused asylum in Switzerland"). The 7-point Likert-type scale ranges from 1 (Don't agree at all) to 7 (Totally agree).

\section{2 | Results}

\subsection{1 | Descriptive results}

As for Study 1, most participants (88\%) named up to 7 alters. The mean is very high $(M=6.40)$ with a relatively low standard deviation $(S D=1.07)$. Regarding the distribution of the injunctive network norms about humanitarian help for migrants, respondents self-reported, on average, that their alters' norms are slightly positive $(M=3.45 ; S D=0.90)$. In comparison to Study 1 , these norms are less positive. Twenty-four percent of the participants indicated that their alters are, on average, opposed to the help provided to migrants. This is in line with the different public in Study 2, which focuses on non-mobilized citizens. Network density ranges between 0 and $1(M=0.55 ; S D=0.23)$ and participants mentioned, on average, 6.40 alters $(S D=1.70)$.

As expected, bivariate correlations reveal that Injunctive Network Norms are positively related to both Immigration as Selfdefining Attitude and Intention to Participate in Helping Behaviors (see Table 3). Results also show a positive correlation between Immigration as Self-defining Attitude and Intention to Participate in Helping Behaviors.

\subsubsection{Multiple regression analysis}

Using PROCESS macro (Hayes, 2018, Model 8), we tested the indirect relationship presented in Figure 1 (see Table 4). Injunctive Network Norms is the predictor, Immigration Attitudes as SelfDefining Attitude is included to test the indirect relation, Intention to Participate in Helping Behaviors is the criterion variable, and Network Density is the moderator of the link between Injunctive Network Norms and both the Self-Defining Attitude and the dependent variable. Numbers of alters, age and gender were included as control variables. Results show that Injunctive Network Norms are significantly related to Immigration Attitudes as SelfDefining Attitude, 95\% Cl $[0.20,1.36]$. Moreover, as expected, Immigration Attitudes as Self-Defining Attitude is positively related to Intention to Participate in Helping Behaviors, 95\% Cl [0.02, 0.24]. The total model, $95 \% \mathrm{Cl}[0.89,1.26]$, and all conditional indirect relations are significant. The direct relation also remains significant, $95 \%$ $\mathrm{Cl}[0.94,1.93]$. Finally, Network Density is not related to intention to participate in helping actions. Since none of the other control variables (i.e., number of alters, age, gender) had a significant effect, we do not report them.

\section{3 | Discussion}

These results replicate findings of Study 1 with a qualitatively different sample, providing support for a positive (and strong) link between involvement in helping behaviors and injunctive network norms. Moreover, although the correlational nature of our data does not allow determining causality, our results show that the extent to which immigration attitudes are considered as self-defining plays a significant role in the link between injunctive network norms and intention to participate in helping behaviors. As in Study 1, network density does not moderate this process.

\section{4 | GENERAL DISCUSSION}

This research provides novel insights into research on intergroup helping, which has thus far mainly been focused on the impact of individual or interpersonal factors, and, to a lesser extent, group membership. It examines the relation between injunctive network norms and helping behaviors in favor of migrants. By taking into account personal social networks, we demonstrate how interactions with significant others-or alters-are related to a person's intention to engage in helping actions. In Study 1, we confirm the link between perceived injunctive norms and volunteers' intention to maintain their engagement. The more their network is perceived as having a
TAB LE 3 Descriptive statistics and bivariate correlations (Study 2 )

\begin{tabular}{|c|c|c|c|c|c|}
\hline & & 1 & 2 & 3 & 4 \\
\hline 1. & Injunctive network norms & & & & \\
\hline 2. & $\begin{array}{l}\text { Immigration as a self-defining } \\
\text { attitude }\end{array}$ & $.24^{* *}$ & & & \\
\hline 3. & $\begin{array}{l}\text { Intention to participate in } \\
\text { humanitarian actions }\end{array}$ & $.60^{* *}$ & $.25^{* *}$ & & \\
\hline \multirow[t]{3}{*}{4.} & Network density & -.10 & .05 & -.03 & \\
\hline & M & 3.45 & 4.48 & 4.39 & 0.54 \\
\hline & $S D$ & 0.90 & 1.56 & 1.62 & 0.23 \\
\hline
\end{tabular}

Notes:: Values in boldface are statistically significant.

$N=247$,

${ }^{* *} p<.01$ 


\begin{tabular}{|c|c|c|c|}
\hline & $b$ & SE & 95\%C.I. \\
\hline \multicolumn{4}{|l|}{ Total effect } \\
\hline $\begin{array}{l}\text { Injunctive Network Norms to Intention to } \\
\text { Participate in Helping Actions (a) }\end{array}$ & 1.08 & 0.09 & {$[0.89,1.26]$} \\
\hline \multicolumn{4}{|l|}{ Direct effect } \\
\hline Injunctive Network Norms to DV (a') & 1.03 & 0.09 & {$[0.84,1.22]$} \\
\hline Network Density to DV & 0.17 & 0.37 & {$[-0.54,0.89]$} \\
\hline Interaction Network Density*IV (d) & -0.73 & 0.41 & {$[-1.54,0.07]$} \\
\hline \multicolumn{4}{|l|}{ Path from IV to self-defining attitude } \\
\hline Injunctive Network Norms (b) & 0.45 & 0.11 & {$[0.24,0.67]$} \\
\hline Network Density & 0.57 & 0.43 & {$[-0.29,1.42]$} \\
\hline Interaction Network Density*IV (e) & -0.60 & 0.49 & {$[-1.56,0.36]$} \\
\hline \multicolumn{4}{|l|}{ Path from self-defining attitude to DV } \\
\hline $\begin{array}{l}\text { Self-defining attitude to intention to } \\
\text { participate in helping actions (c) }\end{array}$ & 0.13 & 0.05 & {$[0.02,0.24]$} \\
\hline \multicolumn{4}{|l|}{ Conditional indirect effects } \\
\hline \multicolumn{4}{|l|}{ Indirect effect through self-defining attitude } \\
\hline Low density & 0.08 & 0.04 & {$[0.01,0.17]$} \\
\hline Medium density & 0.06 & 0.03 & {$[0.01,0.13]$} \\
\hline High density & 0.04 & 0.03 & {$[0.01,0.11]$} \\
\hline
\end{tabular}

TABLE 4 Results for the indirect effect analysis of the link between injunctive network norms and intention to participate in helping actions (Study 2)

Note: $N=247$. All variables were mean centered.

Bootstrap samples $=1,000$.

positive attitude toward immigration, the more the respondents intend to participate in future helping actions. Our results support this relationship even after controlling for initial motivations to engage in volunteerism. Study 2 replicates this pattern in a non-mobilized sample. Extending existing literature on the influence of social embeddedness on helping behaviors (see van Leeuwen \& Zagefka, 2017), we demonstrate that the injunctive norms within these personal social networks play a critical role in engagement in intergroup helping.

Study 1 also highlights the independent effect of descriptive network norms. Indeed, the perceived proportion of alters involved in actions providing assistance to migrants is relatively high (i.e., $42,1 \%$ of the alters) and relates to the intention to provide helping behaviors. This is in line with Smith and Louis' (2008) results that highlight the independent effect of both injunctive and descriptive group norms on political activism.

Study 2 also examines the role of self-definition in the relationship between injunctive norms and helping. Our results demonstrate that the more positive the injunctive norms of a personal social network are toward solidarity with migrants, the more immigration attitudes are considered to be self-defining, and the more the individual is prone to engage in helping behaviors. Thus, meso-level social structures (i.e., social networks) are closely related to individual-level predictors of participation in helping behaviors. Our results imply that alters have the potential to influence a person's engagement in a helping behavior, and that the perception of these alters' norms becomes integrated in a person's identity and self-concept. This suggests that outside pressure is slowly internalized: the more a person perceives their action as consistent with their alters' norms, the more they will self-identify with this norm and engage in actions (Marta, Manzi, Pozzi, \& Vignoles, 2014).

However, we cannot exclude the opposite causal effect. Indeed, a limitation of our two studies inherent to social network analysis is the correlational nature of the data. Conversely to the internalization process, the link between injunctive networks norms and the extent to which immigration attitude is self-defining could be due to a selection process. Because people tend to be attracted to those who are similar to them, they might select, in their personal network, people who share similar characteristics. Past literature has indeed provided extensive support for a selection effect within social networks (e.g., McPherson et al., 2001). Within a highly polarized society regarding immigration issues, people may be more willing to select social peers who share similar attitudes toward immigration. Future studies could address this causality issue either by adopting a longitudinal approach or by manipulating experimentally the normative network context.

Three other methodological limitations should be acknowledged. First, we measured perceived injunctive norms and not actual norms. However, the relationship between perceived norms and behavior has received much empirical support (Manning, 2009, for a meta-analytic review). Indeed, within the social network literature, there is empirical evidence on the relationship between the perceived norm and the alter's actual attribute (Kashima, Wilson, Lusher, Pearson, \& Pearson, 2013). Other social network approaches, such as complete networks and snowball networks, would allow testing the effect of both perceived and actual norms (see, Wölfer \& Hewstone, 2017). In the same vein, we focused on 
behavioral intentions and not actual behaviors. Our results thus make it difficult to differentiate between genuine intentions and extrinsic compliance with the personal social network. Again, a longitudinal design focusing on actual behaviors could be used to address this issue.

Second, although our results highlight the relevance of a social network approach, we find that network density does not play a significant role in the intention to participate in helping actions. More specifically, we expected that the higher the level of interconnection between the alters (i.e., network density), the greater the link between injunctive norms and the intention to engage in such actions. However, our results do not support this prediction. This suggests that, regardless of the structure of the network, the perception of norms plays a role on participation in action. This result implies that it is particularly important to differentiate the normative and structural dimension of personal social networks when adopting a social network approach on solidarity issues. The results regarding network structure also suggest that further research using alternative network approaches should be conducted. Different name generator approaches could be adopted to highlight other types of networks for which structure could have a greater impact. For instance, some approaches make it possible to assess not only networks with strong emotional ties, but also personal networks based on people with whom the participant has interacted over a certain period of time (Marin \& Hampton, 2007).

Third, while the present article focused exclusively on helping migrants, solidarity behaviors are not limited to benevolent actions. Solidarity-based actions can indeed be distinguished in terms of intention (van Leeuwen, 2017), consequences (Halabi \& Nadler, 2017) or nature (Thomas \& McGarty, 2018). In this research, we examined the relation between injunctive norms and a specific form of solidarity-based action associated with humanitarianism or benevolence. This form of helping behavior is commonly distinguished from activismalthough some authors suggest that this dichotomy is not as clear cut as one might expect (Vandevoordt \& Verschraegen, 2019). One could thus argue that similar processes occur for political activism. Indeed, Kende et al. (2017) show that identification with opinion-based groups predicts both outcomes (volunteerism and activism). Likewise, Smith and Louis (2008) show that injunctive group norms exert a significant influence on political attitudes and intentions. Therefore, injunctive norms of a personal social network concerning political actions should also increase intentions to engage in such actions.

Taking a step further, one could even hypothesize that personal social networks play a role in producing collective actions. Van Bezouw and Kutlaca (2019) demonstrate that emphasizing the grievances shared with their close community leads people to engage in collective actions. Inasmuch as they are predicted by a politicized identity (van Zomeren, Postmes, \& Spears, 2008) and moral convictions (van Zomeren, Kutlaca, \& Turner-Zwinkels, 2018), we can assume that the internalization of injunctive network norms creates a self-defining politicized group identity that drives individuals to mobilize as group members, thus engaging in collective actions.

Finally, the present article has important practical implications for the development of interventions that can prompt large numbers of individuals to exhibit such other-benefiting behaviors. While social norms are often formed and taught inadvertently through daily interactions (e.g., Deutsch \& Gerard, 1955), our results suggest that making behaviors more visible to significant others can accelerate the diffusion of helping behaviors across social networks. In line with Paluck (2011) and Rogers, Goldstein, and Fox (2018), another effective communication strategy is to focus on people who have many connections in a social network and who, therefore, can establish-or reaffirm the existence of-norms among numerous social peers. To conclude, the present study provides insights for future research by showing the opportunities offered by a social network approach for psychologists conducting research on social influence, norms and behavioral change in the context of intergroup helping and solidarity.

\section{CONFLICT OF INTERESTS}

The Authors declare that there is no conflict of interest.

\section{ETHICAL STATEMENT}

The manuscript adheres to APA Code of Conduct ethical guidelines.

\section{TRANSPARENCY STATEMENT}

Database and measures of Study 2 and measures of Study 1 are publicly available on the Open Science Framework repository. Link: https://osf.io/f4uxg/

\section{ORCID}

Antoine Roblain (D) https://orcid.org/0000-0003-4542-6702

Emilien Paulis (iD https://orcid.org/0000-0001-5954-4182

\section{REFERENCES}

Aeby, G. (2016). Who are my people? Strengths and limitations of ego-centred network analysis: A case illustration from the Family times survey. FORS Working Paper Series, 2.

Bader, D. (2018). Who ought to stay? Asylum policy and protest culture in Switzerland. In S. Rosenberger, V. Stern \& N. Merhaut (Eds.), Protest movements in asylum and deportation (pp. 69-86). Cham, Switzerland: Springer.

Baumgärtel, M., \& Oomen, B. (2019). Pulling human rights back in? Local authorities, international law and the reception of undocumented migrants. Journal of Legal Pluralism and Unofficial Law, 51(2), 172-191. https://doi.org/10.1080/07329113.2019.1624942

Becker, J. C., \& Tausch, N. (2015). A dynamic model of engagement in normative and non-normative collective action: Psychological antecedents, consequences, and barriers. European Review of Social Psychology, 26(1), 43-92. https://doi.org/10.1080/10463283.2015.1094265

Bienenstock, E. J., Bonacich, P., \& Oliver, M. (1990). The effect of network density and homogeneity on attitude polarization. Social Networks, 12(2), 153-172. https://doi.org/10.1016/0378-8733(90)90003-R

Burt, R. (1984). Network items and the General Social Survey. Social Networks, 6(4), 293-339. https://doi.org/10.1016/03788733(84)90007-8

Christakis, N., \& Fowler, J. (2009). Connected. How your friends' friends' friends affect everything you feel, think and do. New York, NY: Back Bay Book.

Cialdini, R. B., Kallgren, C. A., \& Reno, R. R. (1991). A focus theory of normative conduct: $A$ theoretical refinement and reevaluation of the role of norms in human Behavior. Advances in Experimental Social Psychology, 24, 201-234. https://doi.org/10.1016/S0065-2601(08)60330-5 
Cialdini, R. B., Reno, R. R., \& Kallgren, C. A. (1990). A focus theory of normative conduct: Recycling the concept of norms to reduce littering in public places. Journal of Personality and Social Psychology, 58, 1015-1026. https://doi.org/10.1037/0022-3514.58.6.1015

Clary, E. G., \& Snyder, M. (1991). A Functional analysis of altruism and prosocial behavior: The case of volunteerism. Review of Personality and Social Psychology, 12, 119-148.

Clary, E. G., \& Snyder, M. (1999). The motivations to volunteer: Theoretical and practical considerations. Current Directions in Psychological Science, 8(5), 156-159. https://doi.org/10.1111/1467-8721.00037

Crandall, C. S., Eshleman, A., \& O'Brien, L. (2002). Social norms and the expression and suppression of prejudice: The struggle for internalization. Journal of Personality and Social Psychology, 82(3), 359-377. https://doi.org/10.1037//0022-3514.82.3.359

Crossley, N., Bellotti, E., Edwards, G., Everett, M. G., Koskinen, J., \& Tranmer, M. (2015). Social network analysis for ego-nets. London, UK: Sage.

della Porta, D. (2018). Contentious moves: Mobilising for refugees' rights. In D. della Porta (Eds.), Solidarity mobilizations in the 'Refugee Crisis', Palgrave studies in european political sociology. (pp. 1-38). Cham, Switzerland : Palgrave Macmillan. https://doi.org/10.1007/978-3319-71752-4_1

Deutsch, M., \& Gerard, H. B. (1955). A study of normative and informational social influences upon individual judgment. Journal of Abnormal and Social Psychology, 51, 629-636. https://doi.org/10.1037/ h0046408

Fishbein, M., \& Ajzen, I. (1975). Belief, attitude, intention, and behavior: An introduction to theory and research. Reading, MA: Addison-Wesley.

Gabriel, U., Beyeler, G., Däniker, N., Fey, W., Gutweniger, K., Lienhart, M., \& Gerber, B. L. (2001). Perceived sexual orientation and helping behaviour the wrong number technique, a Swiss Replication. Journal of Cross-Cultural Psychology, 32(6), 743-749. https://doi. org/10.1177/0022022101032006008

Halabi, S., \& Nadler, A. (2017). The intergroup status as helping relations model: Giving, seeking and receiving help as tools to maintain or challenge social inequality. In E. van Leeuwen \& H. Zagefka (Eds.), Intergroup helping (pp. 205-221). Cham, Switzerland: Springer.

Hayes, A. F. (2018). Introduction to mediation, moderation and conditional process analysis, 2nd ed. London, UK: Guilford Press.

Hogg, M. A., \& Abrams, D. (1988). Social identifications. London, UK: Routledge.

Hutter, S., \& Giugni, M. (2009). Protest politics in a changing political context: Switzerland, 1975-2005. Swiss Political Science Review, 15(3), 427-461. https://doi.org/10.1002/j.1662-6370.2009.tb001 41. $\mathrm{X}$

Kashima, Y., Wilson, S., Lusher, D., Pearson, L. J., \& Pearson, C. (2013). The acquisition of perceived descriptive norms as social category learning in social networks. Social Networks, 35(4), 711-719. https:// doi.org/10.1016/j.socnet.2013.06.002

Kende, A., Lantos, N. A., Belinszky, A., Csaba, S., \& Lukács, Z. A. (2017). The politicized motivations of volunteers in the refugee crisis: Intergroup helping as the means to achieve social change. Journal of Social and Political Psychology, 5(1), 260-281. https://doi. org/10.5964/jspp.v5i1.642

Klandermans, B. (1984). Mobilization and participation: Socialpsychological expansions of resource mobilization theory. American Sociological Review, 49(5), 583-600. https://doi.org/10.2307/2095417

Klandermans, P. G. (2014). Identity politics and politicized identities: Identity processes and the dynamics of protest. Political Psychology, 35(1), 1-22. https://doi.org/10.1111/pops.12167

Knoke, D. (1990). Networks of political action: Toward theory construction. Social Forces, 68(4), 1041-1063. https://doi. org/10.2307/2579133

Lazer, D., Rubineau, B., Chetkovich, C., Katz, N., \& Neblo, M. (2010). The coevolution of networks and political attitudes. Political
Communication, 27(3), 248-274. https://doi.org/10.1080/10584 609.2010.500187

Louis, W. R., Thomas, E., Chapman, C. M., Achia, T., Wibisono, S., Mirnajafi, Z., \& Droogendyk, L. (2019). Emerging research on intergroup prosociality: Group members' charitable giving, positive contact, allyship, and solidarity with others. Social and Personality Psychology Compass, 13(3), e12436. https://doi.org/10.1111/spc3.12436

MarinA., \& Hampton, K. N. (2007). Simplifying the personal network name generator. Field Methods, 19(2), 163-193. https://doi. org $/ 10.1177 / 1525822 \times 06298588$

Marsden, P. (2011). Survey methods for network data. In J. Scott \& P. Carrington (Eds.), The SAGE handbook of social network analysis (pp. 370-388). London, UK: Sage.

Marta, E., Manzi, C., Pozzi, M., \& Vignoles, V. L. (2014). Identity and the theory of planned behavior: Predicting maintenance of volunteering after three years. The Journal of Social Psychology, 154(3), 198-207. https://doi.org/10.1080/00224545.2014.881769

McPherson, M., Smith-Lovin, L., \& Cook, J. M. (2001). Birds of a feather: Homophily in social networks. Annual Review of Sociology, 27, 415444. https://doi.org/10.1146/annurev.soc.27.1.415

Merluzzi, J., \& Burt, R. (2013). How many names are enough? Identifying network effects with least set of listed contacts. Social Networks, 35(1), 331-337.

Mescoli, E., Reidsma, M., Diels, E., Hondeghem, A., Mazzola, A., Roblain, A., \& Rea, A. (2019). Mobilizations and opinions regarding asylum seekers, refugees and undocumented migrants in Belgium: Frames, motivations and actions. In A. Rea, M. Martiniello, A. Mazzola \& B. Meuleman (Eds.), The refugee reception crisis in Europe polarized opinions and mobilizations, (pp. 171-224). Brussels, Belgium: Editions de I'Université de Bruxelles.

Nadler, A. (2002). Inter-group helping relations as power relations: Maintaining or challenging social dominance between groups through helping. Journal of Social Issues, 58, 487-502. https://doi. org/10.1111/1540-4560.00272

Omoto, A. M., \& Snyder, M. (1990). Basic research in action: Volunteerism and society's response to AIDS. Personality and Social Psychology Bulletin, 16, 152-165. https://doi.org/10.1177/0146167290161011

Omoto, A. M., \& Snyder, M. (1995). Sustained helping without obligation: Motivation, longevity of service, and perceived attitude change among AIDS volunteers. Journal of Personality and Social Psychology, 68, 671-686. https://doi.org/10.1037/0022-3514.68.4.671

Omoto, A. M., \& Snyder, M. (2002). Considerations of community: The context and process of volunteerism. American Behavioral Scientist, 45(5), 846-867+762. https://doi.org/10.1177/0002764202045005007

Paluck, E. L. (2011). Peer pressure against prejudice: A high school field experiment examining social network change. Journal of Experimental Social Psychology, 47(2), 350-358. https://doi.org/10.1016/j. jesp.2010.11.017

Paulis, E. (2018). Party Members in Context. Social networks and local branches as context for party membership and activism. Doctoral dissertation. Brussels, Belgium: Université libre de Bruxelles.

Penner, L. A., Dovidio, J. F., Piliavin, J. A., \& Schroeder, D. A. (2005). Prosocial behavior: Multilevel perspectives. Annual Review of Psychology, 56(1), 365-392. https://doi.org/10.1146/annur ev.psych.56.091103.070141

Petty, R. E., \& Krosnick, J. A. (1995). Attitude strength: Antecedents and consequences. Mahwah, NJ: Erlbaum Associates.

Rea, A., Martiniello, M., Mazzola, A., \& Meuleman, B. (2019). The refugee reception crisis: Polarized opinions and mobilizations. Retrieved from http://www.oapen.org/record/1005529.

Rogers, T., Goldstein, N. J., \& Fox, C. R. (2018). Social mobilization. Annual Review of Psychology, 69(1), 357-381. https://doi.org/10.1146/annur ev-psych-122414-033718

Rosenberger, S. (2018). Political protest in asylum and deportation. An introduction. In S. Rosenberger, V. Stern \& N. Merhaut (Eds.), Protest 
movements in asylum and deportation (pp. 3-25). Cham, Switzerland: Springer.

Shang, J., \& Croson, R. (2009). A field experiment in charitable contribution: The impact of social information on the voluntary provision of public goods. The Economic Journal, 119(540), 1422-1439. https:// doi.org/10.1111/j.1468-0297.2009.02267.x

Sherif, M. (1966). Group conflict and cooperation. London, UK: Routledge and Kegan Paul.

Simon, B., Stürmer, S., \& Steffens, K. (2000). Helping individuals or group members? The role of individual and collective identification in AIDS volunteerism. Personality and Social Psychology Bulletin, 26(4), 497506. https://doi.org/10.1177/0146167200266008

Sinclair, B. (2012). The social citizen. Peer networks and political behavior. Chicago, IL: University of Chicago Press.

Smith, J. R., \& Louis, W. R. (2008). Do as we say and as we do: The interplay of descriptive and injunctive group norms in the attitude-behaviour relationship. British Journal of Social Psychology, 47(4), 647666. https://doi.org/10.1348/014466607X269748

Snyder, M. (1993). Basic research and practical problems: The promise of a "functional" personality and social psychology. Personality and Social Psychology Bulletin, 19, 251-264. https://doi.org/10.1177/01461 67293193001

Snyder, M., \& Omoto, A. M. (2008). Volunteerism: Social issues perspectives and social policy implications. Social Issues and Policy Review, 2, 1-36. https://doi.org/10.1111/j.1751-2409.2008.00009.x

Stürmer, S., Snyder, M., \& Omoto, A. M. (2005). Prosocial emotions and helping: The moderating role of group membership. Journal of Personality and Social Psychology, 88(3), 532-546. https://doi. org/10.1037/0022-3514.88.3.532

Tajfel, H., \& Turner, J. C. (1986). The social identity theory of intergroup behaviour. In S. Worchel \& W. G. Austin (Eds.), Psychology of intergroup relations (pp. 7-24). Chicago, IL: Nelson-Hall.

Thomas, E. F., \& McGarty, C. (2018). Giving versus acting: Using latent profile analysis to distinguish between benevolent and activist support for global poverty reduction. British Journal of Social Psychology, 57(1), 189-209. https://doi.org/10.1111/bjso.12228

Turner-Zwinkels, F., van Zomeren, M., \& Postmes, T. (2015). Politicization during the 2012 U.S. Presidential Elections: Bridging the personal and the political through an identity content approach. Personality and Social Psychology Bulletin, 41(3), 433-445. https://doi. org/10.1177/0146167215569494

van Bezouw, M. J., \& Kutlaca, M. (2019). What do we want? Examining the motivating role of goals in social movement mobilization. Journal of Social and Political Psychology, 7(1), 33-51. https://doi.org/10.5964/jspp. v7i1.796

\section{APPENDIX}

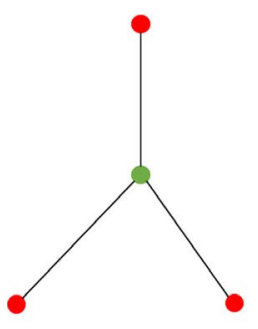

Density $=0$

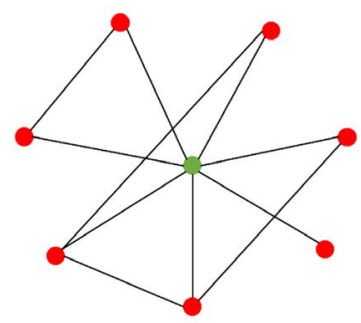

Density $=.19$

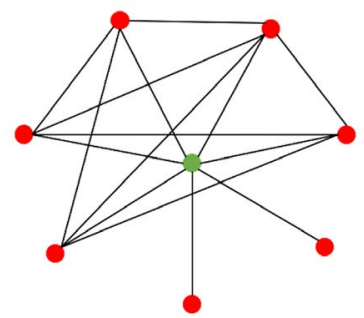

Density $=.38$

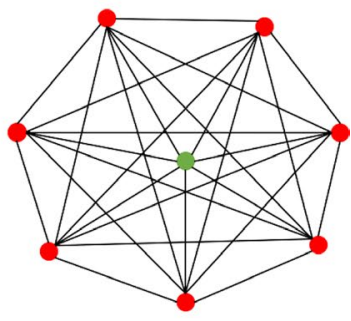

Density $=1$

FIGURE A1 Ego-network visualizations performed via Enet for respondents of Study 1. The first example refers to a respondent (ego, green node) with 3 alters (red nodes) who do not know each other (very low density), whereas the last example shows a "clique" network in which ego's 7 alters know each other (maximum density) [Colour figure can be viewed at wileyonlinelibrary.com] 